\title{
Research on the Benefits of Self-assessment for Business Excellence
}

\author{
Liu Hongzhen \\ International School \\ Wuhan University of Science and Technology \\ Wuhan, China \\ e-mail: liuhongzhen10@hotmail.com
}

\begin{abstract}
In discussing the importance of self-assessment benefits and the maturity of the quality management system in attaining these benefits, it is necessary to recognise the intents of implementing ISO 9000 standards. For the SQC organisations which are also ISO 9000 certified, the underlying premise of certification is that the creation of products and services is the result of the established QMS. As such the intent is to maintain the system in achieving the desired quality as benefits for all interested parties. My preliminary study had shown the organisational contexts are reactive to these benefits, despite a strong management involvement and leadership system in setting directions or business excellence.
\end{abstract}

Keywords:self assessment, benefit , importance, quality management

\section{INTRODUCTION}

This paper reviews the reports of self-assessment surveys, where benefits of self-assessment are identified and purported as organisational contexts for business excellence. Surveys with SQC organisations were carried out to determine the importance of self-assessment benefits to the organisations. By associating the benefits to organisational contexts, the empirical analyses provide us with an interpretation of the importance of self-assessment in achieving excellence. Also, included in the studies are effectiveness of quality audits and self-assessments in contributing to these established benefits.

\section{REPORTED SELF-ASSESSMENT SURVEYS}

With the gaining popularity of self-assessment, investigations were also conducted by researchers and institutions to ascertain their effectiveness and benefits to the organisations. Quality Progress conducted a survey in the US amongst their members to find out how the criteria of MBNQA are being used [Bemowski and Stratton, 1995]. About 3,000 surveys were sent out and 840 had responded. Three main findings are drawn from the results:

- the criteria are being used primarily to assess the level of organisational effectiveness and information on how to achieve business excellence,

- the usefulness of the criteria has met or exceeded most of the user's expectations, and

- the criteria are not restrictive and applicable to broad range of industries.

The survey results underline the original intent of Baldrige Award as a national model that would help to improve quality and productivity [NIST, 1995]. Accordingly, the first European survey on self-assessment was funded by COMETT programme of the European Union and supported by the EFQM [Wiele et al 1996]. The study was based on a questionnaire survey which had been carried out by universities from six European countries. The objectives of the research were included:

- To investigate what kind of self-assessment activities that is taking place in organisations.

- To determine the knowledge and awareness of selfassessment methods.

- To identify the reasons for successes and failures of self-assessment methods.

The findings from the survey had indicated that selfassessment is definitely used to identify the strengths and areas for improvement. The results from Wiele et al [1996] also show that there is maturity level in the self-assessment process with number of different stages:

- An organisation has to be fairly advanced to be able to start self-assessment.

- Organisations have to start simply, for example by using quality management specialists as assessors. In these early stages results will be confidential and are private to the unit concerned, and not link to reward or recognition systems.

- Organisations move to a more advanced stage, in which they use line managers as assessors and share the results across units for organisational learning, and link results to recognition and reward programmes.

As concluded by Wiele et al [1996], the major lesson from the survey is that self-assessment has to be linked with improvements identified as important in its business plan.

Porter et al [1998] had reported on the research project funded by the Chartered Institute of Management Accountant (CIMA) Research Foundation. With CIMA support, Bradford University did the research project: "Evaluating the Operation of the EQA Model for Selfassessment”, [Porter et al, 1998], as a follow-up of the pilot project carried out by European Centre for Total Quality Management. Questionnaire approach was used to establish the initial findings and supplemented with in-depth case studies involving structured interviews with senior management and semi-structured focus groups. The research demonstrated that self-assessment is well established in organisations actively involved in TQM initiatives, and there 
is an increasing interest in applying the EQA model for business excellence. By far the most important reasons for organisations starting self-assessment are:

- to provide a driver for continuous improvement and

- $\quad$ to identify areas for improvement.

The benefits gained from self-assessment matched these reasons remarkably well and demonstrated that intent of selfassessment was achieved. Organisations have adopted the EQA model in various innovative ways but with a constancy of purpose and results achieved. From the results of European research, MacKerron and McGlynn [200] had concluded that most European organisations do not embark on the process of self-assessment to win an award but to help them on their journey for business excellence.

The surveys conducted by the institutions and researchers are comprehensive, with the intention of establishing the benefits of self-assessment that are important to the organisations. However, I feel that issues pertinent to the maturity of the organisations in addressing self-assessment are not adequately addressed. Also, it is not clear how the benefits of self-assessment can be rationalised to improve the organisations' performance, since there is no association between these benefits to the organisational contexts. Davis et al [1996] had argued that for organisations to reap the benefits from self-assessment, the process should provide:

- sense of direction with alignment to goals and objectives,

- objective evidence that supports the assessment, and

- a rigorous and structured approach to business improvement.

My opinion is that most organisations recognise that selfassessment can help to increase the pace of performance improvement, but the importance of self-assessment benefits have to be established to ensure that the intents of the process is understood.

\section{BENEFITS OF SELF-ASSESSMENT}

The challenges of self-assessment are to establish the business excellence intents, understand the benefits of the process and identify an appropriate model in which an organisation can judge its own levels of performance. In conducting self-assessment top management must define the intents and purpose. Organisations will only benefit if the model is significant in discerning the weaknesses of quality management and an interpretation of reality, with the capability to understand the generic issues pertinent to business process and performance improvement. In addition to the reasons for undertaking self-assessment, organisations have to determine the importance of these benefits that can be derived from the process. As the primary derivatives from self-assessment, they have to be evaluated in association to the maturity of quality management.

Instead of carrying out an empirical research in determining the different benefits of self-assessment, my approach is to identify the benefits reported by different researchers and use this information to find out their importance to the SQC organisations and maturity of their quality management system in attaining these benefits. Through literature reviews the benefits that can be derived from self-assessment are collated from different researchers. As Porter and Tanner [1996] had pointed out that these benefits are the common threads of improvement and focused on the real needs of business running. In this thesis, they are used for learning the SQC organisations' intents for business excellence and their effectiveness as baseline for quality audit and self-assessment. In this paper these benefits are purported by the contextual assumptions in understanding the benefits of business excellence, and how they can be attained through self-assessment:

- Planning: As a strategy Planning reflects the organisation's leadership system in attaining these benefits that are pertinent in the development of organisational purpose, vision and values. Items 1 to 5 are self-assessment benefits that can be derived from leadership involvement and commitment to Planning context. It establishes performance measures as a "baseline" for assessment, evaluation and planning, which helps to facilitate management in developing and translating strategy into action plans that involve all levels of the organisations.

- People: This context is concerned with selfassessment benefits that underline organisation's development of people that is committed to customers and stakeholders, and to achieve objectives for the organisations. For People context, Items 6 to 10 are benefits that increase the awareness of employees, stakeholders and customers in the organisational drives for business excellence. This is also permeated as shared values which improve employees' commitment in meeting the internal needs and satisfying the external customers. Self-assessment benefits in this context facilitate development and reinforcement of the workforce by improving the core competencies and skill sets, promoting organisational learning and involvement in performance improvement across the organisations.

- Project: Project context is related to the management of resources, with effective use of information and core competencies of people as the means by which improvement results are achieved. Items 11 to 15 are self-assessment benefits which contribute to the organisation's performance improvement by effective management of these resources. The benefits supplement organisational learning through the integration of quality initiatives, developing cross-functional teams and resources for improvements, with effective use of information in supporting projects and reinforcing communications throughout the organisations. 
- Performance: This context establishes the benefits that enable organisations to manage and improve their processes. The benefits that can be derived from Performance context also reflect the intents of business excellence and as baselines for improving overall performance of the organizations. Items 16 to 20 enhance factual decisions in performance improvement by monitoring and evaluating the organisation's capability in meeting customers' requirements and expectations. The self-assessment benefits articulate the importance of meeting business improvement objectives and of using relevant results for management decision making.

It should be noted that benefits of self-assessment are in-exhaustive; nevertheless those that had been identified from the literature reviews are sufficient for me in instituting my preliminary study of quality assessment. In Singapore, there is very little empirical study in the benefits of self-assessment, and my purpose is to establish their importance to SQC organisations and their maturity in attaining these benefits. This includes the effectiveness of quality audit and self-assessment. The underlying reasons for using the self-assessment benefits in my empirical study are also given:

- $\quad$ The summary is based on comprehensive findings conducted by different researchers and their conclusions on the benefits of self-assessment. Hence; they can be deemed as the desired outcomes of adopting self-assessment models.

- By understanding the importance of selfassessment benefits, it can help SQC organisations to focus on the factors and develop strategies that need to be addressed in becoming world-class organisation.

- The list will also promote the usefulness of selfassessment. By determining the importance of selfassessment benefits, it provides fact-based guidance to the SQC organisations regarding the investment of resources in the areas for improvement.

\section{SURVEY OF SQC ORGANISATIONS}

\section{A. Intents of survey}

In studying the state-of-the-art on self-assessment Wiele et al [1995] had concluded that organisations with selfassessment activities are, in general, positive about its value and see many improvements flowing from it. Similarly, with inception of the SQA model, there has been an increasing interest in self-assessment and for public services it is encouraged under the Public Service 21 Directive [PS21 Office 2001]. This is despite the difficulty in establishing a direct relation between self-assessment benefits to operational performances and as a process in evaluating the maturity of quality management. However, by establishing benefits of self-assessment within the organisational contexts, results of my findings were also shared with responding organisations. This had helped to create their awareness of self-assessment benefits and focus on areas that can be enhanced for pursuing business excellence. In establishing the different findings it is also my intent to understand the effect of these benefits to quality audit and self-assessment of SQC organisations. Objectives of the empirical study are to determine:

- the importance of self-assessment benefits to the SQC organisation's operations,

- the maturity of the organisations' quality management system in attaining these benefits, and

- effectiveness of quality audit and self-assessment in contributing to the established benefits for business excellence.

The factual findings in this survey are used to hypothesise the organisational contexts as the quality management for business excellence, and as the bases for comparing the effectiveness of BEACON instrument with the IQM system.

\section{B. Data collection}

As the thesis is focused on the criteria of SQA model and ISO 9000 QMS, my survey only involved SQC organisations that are certified to the standards, and the targeted people are respective owners of the SQA criteria. By defining the target group, I was able to concentrate on the respondents who understand the SQA criteria and their underlying reasons for embarking on business excellence. Instead of the normal practices through mails and interviews, data were collected during the SQA workshop sessions and seminars conducted by The Centre for Quality, Ngee Ann Polytechnic, and in-company trainings for the SQC organisations. Breakdown of the targeted group is given in Table 1.

\section{EMPIRICAL ANALYSES}

In the analysis of data, my approach is to associate the organisational contexts to benefits of self-assessment and determine their effect on the organisations. This helped to facilitate the analysis by looking at results from the contextual assumptions before determining the benefits that are pertinent to each of the context. For the purpose of evaluation, Microsoft Excel is used to capture the data entries and compute the percentage score, mean value indicating the average value of data entries and standard deviation to ascertain the spread of the data from the mean. To determine the relationships between quality audit and self-assessment, Pearson correlation is used to determine the associations that underscore the two assessment processes.

\section{A. Frequency of Self-assessment}

Table 2 is a summary on the time interval for quality assessment carry out on the 53 SQC organisations. From the table, it shows that more than half of the cohort carries out self-assessment once a year, with public sectors taking the lead (36\%). This can be due to the influence of Public 
Service 21 Directive, where they are expected to carry out their own evaluations and improvements, and as part of the annual business planning. Out of the 53 SQC organisations $20 \%$ does not carry out self-assessment on an annual basis, and $11 \%$ conduct their own self-assessment before the comprehensive site assessment by PSB. Also in compliance to ISO certification requirements, all the organisations have carried out internal quality audit every six months.

\section{B. Importance of Self-assessment}

Figure 1 portrays the importance of self-assessment benefits in association to the organisational contexts. The scoring is based on the Likert scale from 0 to 5 , where $0=$ not important, $3=$ important and $5=$ very important. Planning context has a mean value of 3.27. From Table 3.4, details of this value show $40 \%(31 \%+9 \%)$ of the respondents had given a rating greater than 3, 39\% had given a rating of 3 indicating their importance and 21\% (2\% + 19\%) had disagreed by having a rating less than 3 . Analysis of Planning context indicates Item Q6.2 (mean value $=0.396$ ), leadership involvement and commitment are important in setting directions for the goals and objectives. This is reinforced by Items Q6.4 (mean value $=3.27$ ) and Q6.5 (mean value $=3.11$ ), where it is also important to facilitate management in achieving consistency of directions in developing strategy and plans that involve all levels of the organisation. The importance of performance measures, Items Q6.1 (mean value $=3.00$ ) which is also associated to Q6.3 in the achievement of goals and objectives (mean value $=3.03$ ) have lower values within the Planning context.

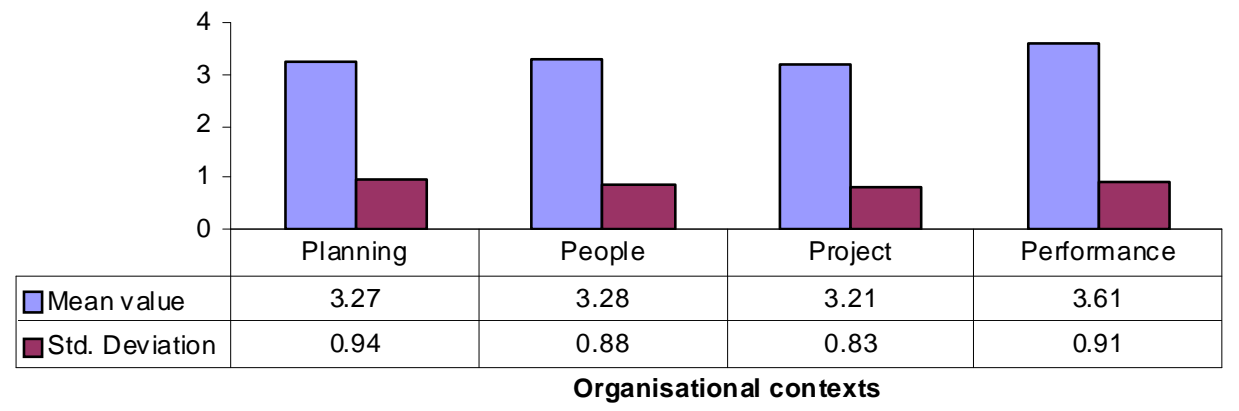

Figure 1 Importance of self-assessment benefits to the SQC organisations

In rating the importance of self-assessment benefits, People context has a score that is below the Performance, with a mean value of 3.28; $19 \%$ of the respondents had given a rating of 2 and less, 38\% with a rating of 3 , and $43 \%$ with a rating that is greater than 3 . Table 3.4 suggests that the importance in developing a workforce that satisfies the customers and stakeholders has a positive effect on the respondents. Items Q6.6 (mean value $=3.58$ ) and Q6.8 (mean value $=3.49$ ) are important to the SQC organisations. These two items suggest that most SQC organisations have communicated their intent for business excellence to employees, stakeholders and customers, and involved the employees in their commitment to improvement. These are also permeated as shared values that are bases for creating a high performance workforce, Item Q6.10 (mean value = 3.29). However, benefits in the People context could not be fully realised if Items Q6.7 (mean value $=3.15$ ) and Q6.9 (mean value $=2.92$ ) are not emphasised. For business excellence, it is also important to improve the core competencies and skills of the people as they contributes to achieving the business objectives, and applying quality management principles in a focused way can enhance shared values and improve commitment of the workforce.

Of the four organisational contexts, Project has a lowest score with a mean value of 3.21. From Table 3.4, 32\% of the respondents had given a rating greater than $3,48 \%$ with a rating of 3 indicating their importance and 20\% had disagreed with rating less than 3 . In this context, respondents had agreed in effective use of information and people as the means by which improvement results are achieved. This is despite the fact there is a strong emphasis in facilitating communication and improvement throughout the organisation, Item Q6.15 (mean value $=3.68$ ). To the respondents, most SQC organisations do regard the importance of information in encouraging best practices and benchmarking opportunities, Items Q6.13 (mean value = 3.03) and Q6.14 (mean value = 3.21). However, these have not been strongly emphasised in the development of people and resources, Item Q6.11 (mean value = 3.10). These have an effect on the organisations' competency, and developing cross-functional team which provides the impetus for business improvement programmes and project management, Item Q6.12 (mean value = 3.03).

\section{CONCLUSION}

Quality assessments will continue to exist in organisations, as long as there are requirements in conformance to reference standards and needs to position organisations' performance with the defined criteria for business excellence, as well as the pressures for performance improvements. In the implementation of IQM system, this issue is addressed by MAG, where self-assessment is enhanced by the objectivity of quality audit. This provides a 
more generic assessment approach that overcomes limitations of the individual approaches.

\section{ACKNOWLEDGMENT}

The author would like to thank Puah Kok Yong for his support and providing invaluable materials and advice.

\section{REFERENCES}

[1] Atkinson,P. [1990] , Creating Culture Change:The Key to Successful Total Quality Management, Bedford:IFS Publications.

[2] Black, S.A. and Crumley, H.C. [1997], "Self-assessment: What's in I for us?”,TQM, Vol. 8, pp.90-93.
[3] Davis, J., Khodabocus, F. and Obray, C. [1996], “Self-assessment: A Path to Business Excellence”, QWTS, March, pp. 4-11

[4] Dyhl [1998]: Quality Award Model for Self-assesmentDevelopment of a Self-Assessment Tool for Automous Production Teams, Master Thesis, Technical University of Denmark..

[5] Deming, W.E., [1986], Out of the Crisis Quality Productivity and Competitive Position, Cambridge, MA: Cambridge University Press.

[6] Kanji, G.K. [2002] Measuring Business Excellence , Routledge, London and New York.

[7] Nationall Institute of Standaeds and Technology [1999], Malcolm Balbridge National Quality 1999 Criteria for Performance Excellence, Gaithersburg,US.

Table 1 Breakdown of survey respondents

\begin{tabular}{|c|c|c|c|c|c|c|c|}
\hline & $\begin{array}{l}\text { Public } \\
\text { Sector }\end{array}$ & $\begin{array}{l}\text { Local } \\
\text { SMEs }\end{array}$ & $\begin{array}{l}\text { Local } \\
\text { Large }\end{array}$ & $\begin{array}{l}\text { Foreign } \\
\text { SMEs }\end{array}$ & $\begin{array}{l}\text { Foreign } \\
\text { Large }\end{array}$ & $\begin{array}{c}\text { SQC } \\
\text { organisations }\end{array}$ & $\begin{array}{l}\text { Number of } \\
\text { respondents }\end{array}$ \\
\hline Manufacturing & & 2 & 2 & & 2 & 6 & 10 \\
\hline Construction & & 2 & & & & 2 & 3 \\
\hline Commerce & & & 2 & & & 2 & 3 \\
\hline $\begin{array}{c}\text { Finance and Business } \\
\text { Services }\end{array}$ & 1 & 1 & 1 & 2 & 1 & 6 & 8 \\
\hline $\begin{array}{l}\text { Transport and } \\
\text { Communications }\end{array}$ & 2 & 1 & 1 & & & 4 & 6 \\
\hline $\begin{array}{c}\text { Community, Social and } \\
\text { Public Services }\end{array}$ & 28 & 2 & 2 & 1 & & 33 & 43 \\
\hline Total & 31 & 8 & 8 & 3 & 3 & 53 & 73 \\
\hline
\end{tabular}

Table 2 Frequency of quality assessment, SQC organisations.

\begin{tabular}{|c|c|c|c|}
\hline \multirow{2}{*}{$\begin{array}{l}\text { Percentage distribution of SQC organisations involve } \\
\text { in self-assessment }\end{array}$} & \multicolumn{2}{|c|}{ Percentage distribution (\%) } & \multirow{2}{*}{$\begin{array}{l}\text { Consolidated } \\
\text { results (\%) }\end{array}$} \\
\hline & $\begin{array}{l}\text { Private } \\
\text { organisations }\end{array}$ & Public sector & \\
\hline 6 months & 9 & 7 & 16 \\
\hline 6 to 12 months & 17 & 36 & 53 \\
\hline More than 12 months & 4 & 16 & 20 \\
\hline Before the comprehensive site assessment by PSB & 7 & 4 & 11 \\
\hline Total percentage & 37 & 63 & 100 \\
\hline Internal quality audit (6 months) & 37 & 63 & 100 \\
\hline
\end{tabular}

